\title{
Multivariate-Statistical Assessment of Heavy Metals for Agricultural Soils in Northern China
}

\author{
Pingguo Yang, ${ }^{1}$ Miao Yang, ${ }^{2}$ Renzhao Mao, ${ }^{3}$ and Hongbo Shao ${ }^{4,5}$ \\ ${ }^{1}$ Shanxi Normal University, Linfen 041000, China \\ ${ }^{2}$ Shanxi Agricultural University, Taigu 030801, China \\ ${ }^{3}$ Center for Agricultural Resources Research, Institute of Genetics and Developmental Biology, \\ Chinese Academy of Sciences, Shijiazhuang 050021, China \\ ${ }^{4}$ Key Laboratory of Coastal Biology \& Bioresources Utilization, Yantai Institute of Coastal Zone Research, \\ Chinese Academy of Sciences (CAS), Yantai 264003, China \\ ${ }^{5}$ Institute for Life Sciences, Qingdao University of Science \& Technology (QUST), Qingdao 266042, China
}

Correspondence should be addressed to Hongbo Shao; shaohongbochu@126.com

Received 26 March 2014; Revised 4 April 2014; Accepted 5 April 2014; Published 16 April 2014

Academic Editor: Xu Gang

Copyright (c) 2014 Pingguo Yang et al. This is an open access article distributed under the Creative Commons Attribution License, which permits unrestricted use, distribution, and reproduction in any medium, provided the original work is properly cited.

\begin{abstract}
The study evaluated eight heavy metals content and soil pollution from agricultural soils in northern China. Multivariate and geostatistical analysis approaches were used to determine the anthropogenic and natural contribution of soil heavy metal concentrations. Single pollution index and integrated pollution index could be used to evaluate soil heavy metal risk. The results show that the first factor explains $27.3 \%$ of the eight soil heavy metals with strong positive loadings on $\mathrm{Cu}, \mathrm{Zn}$, and $\mathrm{Cd}$, which indicates that $\mathrm{Cu}, \mathrm{Zn}$, and $\mathrm{Cd}$ are associated with and controlled by anthropic activities. The average value of heavy metal is lower than the second grade standard values of soil environmental quality standards in China. Single pollution index is lower than 1, and the Nemerow integrated pollution index is 0.305 , which means that study area has not been polluted. The semivariograms of soil heavy metal single pollution index fitted spherical and exponential models. The variable ratio of single pollution index showed moderately spatial dependence. Heavy metal contents showed relative safety in the study area.
\end{abstract}

\section{Introduction}

Soils are critical environments where rock, biology, air, and water interface. Soil pollution has become an important environmental issue in China owing to rapid economic development and industrialization and increasing reliance on agrochemicals in the last few decades [1-3]. Soil heavy metal contents are not only the serious environmental issue but also frequency related to agricultural soil utilization problem [46]. Soil heavy metals could be necessary or beneficial to plants at certain levels but toxic when exceeding specific threshold [7-11]. If these elements are absorbed by the plants through the root system, they may enter the food chain and become toxic to humans and animals. The ecological importance of soil heavy metals is closely related to human health due to their high ecological transference potential.
For agricultural soils, the main pollution sources of heavy metals are due to activities such as irrigation using wastewater, pesticides, agricultural fertilizers, and organic manure, disposal of urban and industrial wastes, and atmospheric pollution from motor vehicles and the combustion of fossil fuels. Heavy metals in agricultural soil have become higher than background levels. It has also become a hot spot for the study of the international soil environment science research and ensured its sustainability.

Multivariate statistical approaches including principal component analysis (PCA) and cluster analysis (CA) are the statistical tools used in the elaboration pollution $[12,13]$. It has been reported that PCA methods have been widely used in geochemical applications to identify soil pollution sources and distinguish natural versus anthropic contribution $[14,15]$. CA is often used coupled to PCA to check results and group 


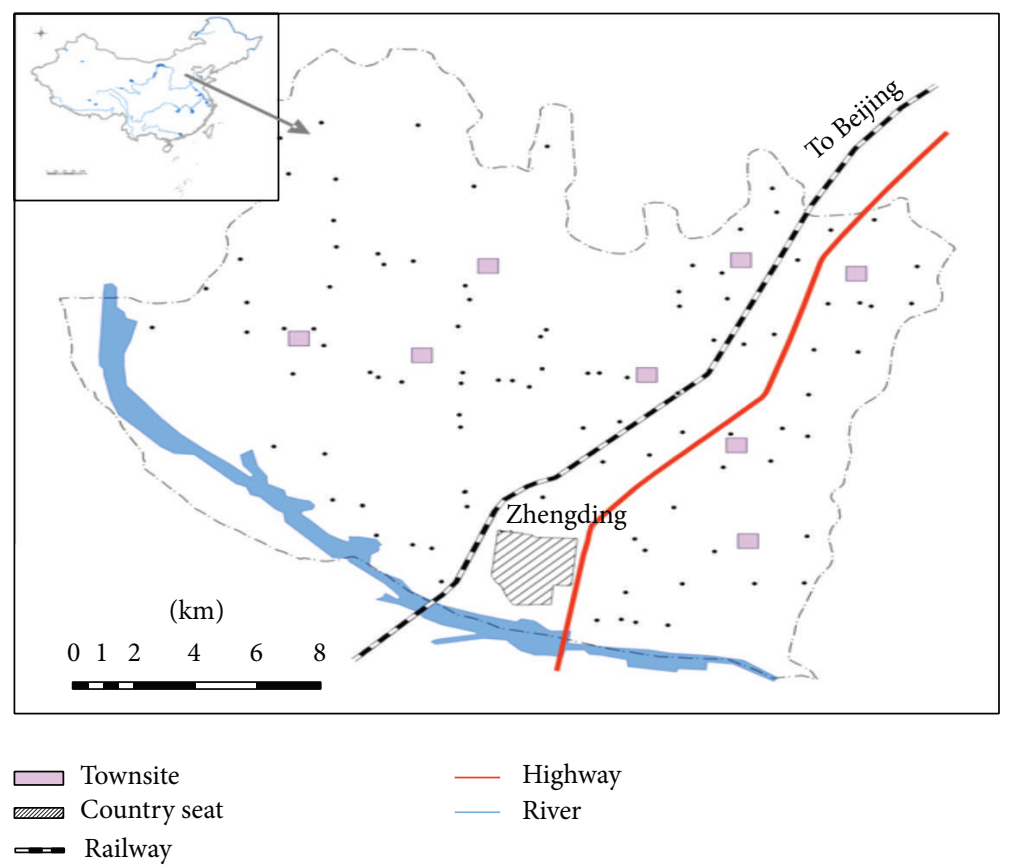

FIGURE 1: Map of the studied area and sampling locations.

individual parameters and variables [16-20]. The methods of geostatistics use the stochastic theory of spatial correlation for both interpolation and for apportioning uncertainty [21]. Geostatistics is based on the theory of a regionalized variable which uses the technique of semivariogram to measure the spatial variability of a regionalized variable and provides the input parameters for the spatial interpolation of kriging $[22,23]$. Geostatistics can also be used to assess the risk of exceeding critical values (regulatory thresholds, soil quality criterion) at unsampled locations and to simulate the spatial distribution of attribute values [21].

The present study is focused on the suburban area of Shijiazhuang city. Zhengding has formed an industrial structure consisting of Shijiazhuang airport, electronic, petrochemical, and highly traffic density undergone a rapid transition from a traditionally agricultural-based to an increasingly industrialbased economy in the last 30 years which could enhance the risk of metal contamination through food chain in the region as heavy metals may enter and accumulate in agricultural soils through atmospheric deposition and irrigation. Early studies in the study area indicated the spatial variability of heavy metal distribution [17].

The study was to analyze possible sources of these heavy metals by multivariate statistical techniques and to assess soil heavy metal contamination using single pollution index and integrated pollution index to identify spatial distribution of single pollution index of soil heavy metal through geostatistical analysis.

\section{Materials and Methods}

2.1. Study Region and Soil Sampling. The study is focused on the suburban area of Shijiazhuang city, northern China. The region is well known for intense industrial and commercial activities. Soil samples were collected from 100 locations in the Zhengding, an administrative district covering $468 \mathrm{~km}^{2}$ with a population of around 467,000 people. This area has a continental monsoon climate with an average annual temperature $13^{\circ} \mathrm{C}$, and an average precipitation of $530 \mathrm{~mm}$. The altitude levels range from $65 \mathrm{~m}$ to $105 \mathrm{~m}$ within the study area. The main soil type is carbonate cinnamon and Chao soil according to China soil classification system. The samples were collected from agricultural areas (mostly wheat, cereals, and vegetables). The coordinates of sampling locations were recorded with GPS. The sampling locations are shown in Figure 1.

2.2. Soil Analyses. Each sample consists of 10 soil cores (0$20 \mathrm{~cm}$ ) depth, $1 \mathrm{~kg}$ ca total weight, which was collected from within a $10 \times 10 \mathrm{~m}$ area with the central point corresponding to the defined position for the sample. All of the samples were air-dried at room temperature and sieved by a $2 \mathrm{~mm}$ mesh and stored in polyethene plastic bags for subsequent sample analysis. Metal concentrations for $\mathrm{Cu}, \mathrm{Zn}, \mathrm{Ni}, \mathrm{Pb}, \mathrm{Cr}, \mathrm{Hg}$, As, and $\mathrm{Cd}$ were analyzed after complete dissolution using a mixture of $\mathrm{HNO}_{3}-\mathrm{HF}-\mathrm{HCLO}_{4}$ and heated in a microwave digestion system, using appropriate atomic absorption spectrometric techniques [17]. The accuracy of the procedure was determined by analyzing the certified reference material GB 7475-87 (National Institute of Standards and Technology, China). Quality controls involved analysis of random samples, blank samples, and national standard samples each time.

2.3. Assessment of Soil Contamination. The assessment of soil heavy metal contamination in agro-ecosystem is often the choice of single pollution index $(\mathrm{Pi})$ and the Nemerow 
TABLE 1: Total variance and component matrixes (three factors selected) for heavy metals.

(a) Total variance explained

\begin{tabular}{|c|c|c|c|c|c|c|c|c|c|}
\hline \multirow{2}{*}{ Component } & \multicolumn{3}{|c|}{ Initial eigenvalues } & \multicolumn{3}{|c|}{ Extraction sums of squared loadings } & \multicolumn{3}{|c|}{ Rotation sums of squared loadings } \\
\hline & Total & $\%$ of variance & Cumulative \% & Total & $\%$ of variance & Cumulative \% & Total & $\%$ of variance & Cumulative \% \\
\hline 1 & 2.700 & 33.752 & 33.752 & 2.700 & 33.752 & 33.752 & 2.187 & 27.338 & 27.338 \\
\hline 2 & 1.464 & 18.304 & 52.056 & 1.464 & 18.304 & 52.056 & 1.639 & 20.484 & 47.822 \\
\hline 3 & 1.264 & 15.797 & 67.853 & 1.264 & 15.797 & 67.853 & 1.602 & 20.030 & 67.851 \\
\hline 4 & 0.893 & 11.160 & 79.013 & & & & & & \\
\hline 5 & 0.630 & 7.871 & 86.884 & & & & & & \\
\hline 6 & 0.479 & 5.987 & 92.871 & & & & & & \\
\hline 7 & 0.362 & 4.523 & 97.394 & & & & & & \\
\hline 8 & 0.208 & 2.600 & 100.000 & & & & & & \\
\hline
\end{tabular}

(b) Component matrixes

\begin{tabular}{lcccccc}
\hline \multirow{2}{*}{ Element } & \multicolumn{3}{c}{ Component matrix } & \multicolumn{3}{c}{ Rotated component matrix } \\
& PC1 & PC2 & PC3 & PC1 & PC2 & PC3 \\
\hline $\mathrm{Cu}$ & 0.838 & 0.231 & 0.117 & $\mathbf{0 . 6 4 8}$ & 0.585 & 0.086 \\
$\mathrm{Zn}$ & 0.804 & 0.236 & -0.325 & $\mathbf{0 . 8 7 5}$ & 0.207 & 0.008 \\
$\mathrm{Ni}$ & 0.549 & -0.593 & 0.335 & 0.125 & 0.367 & $\mathbf{0 . 7 8 5}$ \\
$\mathrm{Pb}$ & 0.317 & 0.028 & 0.727 & -0.153 & 0.756 & 0.182 \\
$\mathrm{Cr}$ & 0.692 & -0.355 & -0.148 & 0.565 & 0.114 & 0.544 \\
$\mathrm{Hg}$ & -0.041 & 0.850 & 0.101 & 0.085 & 0.319 & $-\mathbf{0 . 7 9 1}$ \\
$\mathrm{As}$ & 0.428 & 0.381 & 0.380 & 0.205 & $\mathbf{0 . 6 3 7}$ & -0.156 \\
$\mathrm{Cd}$ & 0.536 & 0.096 & -0.572 & $\mathbf{0 . 7 7 1}$ & -0.166 & 0.013 \\
\hline
\end{tabular}

integrated pollution index $(P)$. Generally $P_{i}$ is defined as the ratio of the heavy metal concentration $C_{i}$ to the second grade standard values according to the Chinese soil environmental quality standards $S_{i}$ (GB15618-1995) [24]:

$$
P_{i}=\frac{C_{i}}{S_{i}}
$$

When $P_{i}<1$, there is no metal pollution; otherwise, if $P_{i} \geq 1$, it means pollution happens.

The Nemerow integrated pollution index $P$ considers not only the mean values of all considered metals but also the maximum value of $P_{i}[25]$. $P$ is determined by the mean value $P_{\text {ave }}$ and the maximum $P_{\max }$ as the following equation:

$$
P=\sqrt{\frac{P_{\max }^{2}+P_{\mathrm{ave}}^{2}}{2}} .
$$

2.4. Statistical Analysis. Multivariate statistical including principal component analysis (PCA), cluster analysis (CA), and geostatistical analysis are powerful tools for distinguishing pollution sources. Semivariograms model for each single pollution index considered elements $(\mathrm{Cu}, \mathrm{Zn}, \mathrm{Ni}, \mathrm{Pb}, \mathrm{Cr}$, and $\mathrm{Hg}$ ) using geostatistics. Classic statistical analyses were processed using SPSS19.0 software. Geostatistical modeling software Variowin 2.2 was used for the calculation of semivariogram of soil heavy metal single pollution index.

\section{Results and Discussion}

3.1. Principal Component Analysis. Summary statistics and normal test of Zhengding datasets were performed and the results were present [17]. PCA can be used to reduce data and to extract a smaller number of independent factors (principal components) to find the relationship among observed variables [16-18]. Principal component analysis (PCA) was applied in the study to have high quality experimental results. The PCA based results for soil heavy metals are listed in Table 1. According to the initial eigenvalues, three principal components are selected, accounting for over $67.8 \%$ of the total variance. The eigenvalues of the three first extracted factors are greater than one. All of the elements are consequently well represented by these three principal components.

The initial component matrix for heavy metals indicates that $\mathrm{Cu}, \mathrm{Zn}$, and $\mathrm{Cd}$ are associated, showing high values in the first principal component (PC1) which explains $27.3 \%$ of the total variance and loads heavily on $\mathrm{Cu}(0.65)$, $\mathrm{Zn}$ (0.88), and $\mathrm{Cd}(0.77)$. $\mathrm{Cu}$ and $\mathrm{Zn}$ values are controlled by a long-term anthropic activity such as pesticides. The second principal component (PC2) includes univocally $\mathrm{Pb}$ and As, which accounts for $20.5 \%$ of the total variance. Common sources of lead in soils are manure, sewage sludge, lead-arsenate pesticides, vehicle exhausts, and industrial fumes. The study area has a high vehicular traffic density, constituted by Zhengding international airport and several important railways, expressway 


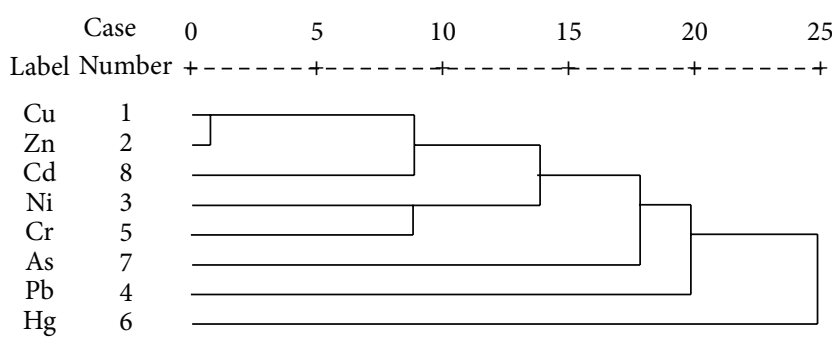

FIGURE 2: Dendrogram results from Pearson correlation coefficients of hierarchical cluster analysis for heavy metals.

(http://www.en.wikipedia.org/wiki/zhengding), for leaded gasoline widely used. The third principal component (PC3) is correlated very strongly with $\mathrm{Hg}$ loading $(-0.79)$ and also by Ni loading (0.79), accounting for $20 \%$ of the total variance.

Long-term and extensive use of pesticides in farmland may cause heavy metals such as copper, nickel, zinc, and cadmium to accumulate in the topsoil $[26,27]$. Common sources of lead in soils include car exhausts, manure, sewage sludge, and coal burning. Cd is present in fossil fuel such as coal and oil and having no functions in plants or animals or human body. In addition, normal agricultural practices may cause enrichment of heavy metals. These practices are an important source of $\mathrm{Zn}, \mathrm{Cu}$, and $\mathrm{Cd}$ due to the application of manure or inorganic fertilizers. Thus in Table 1, the relationship among all of the eight variables is clearly revealed.

3.2. Cluster Analysis. Although not substantially different from PCA, CA could be used as an alternative method to confirm results and provide grouping of variables [5]. The heavy metals concentration data were calculated using the hierarchical clustering with SPSS software. Figure 2 shows the CA results for the heavy metals as a dendrogram in the study area. This figure shows three clusters. (1) $\mathrm{Cu}, \mathrm{Zn}$, and $\mathrm{Cd}$ are very well correlated with each other. The farming area has had several decades of intensive tillage, long-term fertilizer and pesticide application might be a major source of accumulated heavy metals in the study area, (2) which is associated with $\mathrm{Pb}$ and $\mathrm{As} . \mathrm{Pb}$ is mostly found in automobile battery in sufficient amount; excessive intake $\mathrm{Pb}$ can damage the nervous, skeletal, circulatory, enzymatic, endocrine, and immune systems of human body. (3) $\mathrm{Ni}$ and $\mathrm{Hg}$ are commonly associated in a number of rock types or soil parent materials. The analyzed results are in good accordance with the findings of the PCA analysis.

3.3. Hazard Assessment of Soil Heavy Metals. Table 2 shows that the mean contents of $\mathrm{Zn}, \mathrm{Hg}$, and $\mathrm{Cd}$ exceed soil background values, but they are still lower than the Grade II criteria, which mean that the three metal elements are mainly affected by anthropogenic sources. The mean value of soil $\mathrm{Zn}$ $69.96 \mathrm{mg} / \mathrm{kg}$ was higher than its background value $62.0 \mathrm{mg} / \mathrm{kg}$ but it did not exceed the limiting content $300 \mathrm{mg} / \mathrm{kg}$ of SEPA. The average value of $\mathrm{Cd} 0.15 \mathrm{mg} / \mathrm{kg}$ was higher than its background value $0.075 \mathrm{mg} / \mathrm{kg}$. Phosphate fertilizers have been well known as the major external source of soil Cd [26, 27].
Especially $\mathrm{Hg}$ is 3.49 times the background value and mainly originated from industry and traffic sources. $\mathrm{Cu}, \mathrm{Ni}, \mathrm{Pb}, \mathrm{Cr}$, and As concentrations are lower than or approximately equal to their corresponding background values, which indicates that these elements are dominated by natural sources and human activities.

The heavy metal concentrations in Zhengding agricultural soil are compared with the data reported from other areas in the world in Table $2[6,14,17,20]$. The mean content of $\mathrm{Cu}$ and $\mathrm{As}$ is lower than that for other areas. The average values of $\mathrm{Pb}, \mathrm{Hg}$, and $\mathrm{Cd}$ are similar to those of Beijing and Tianjin, but lower than in other areas. The mean concentration of $\mathrm{Cu}, \mathrm{Pb}, \mathrm{Cr}, \mathrm{As}$, and $\mathrm{Cd}$ was lower than those reported by $\mathrm{Hu}$, and within the range reported by Qiao.

The Chinese Environmental Quality Standard for soils (GB 15618-1995) [24] and the soil background values of Hebei were adopted to evaluate the pollution degree. The soil is mainly alkaline in the investigated area. Grade II criteria for soil quality are established to protect agricultural production and to maintain human health. Across the investigated area, a wide range of soil heavy metal concentrations have been measured.

The analyzed results indicate that all of the metal concentrations are below the Environmental Protection Administration for soil in China. The $P_{i}$ of soil heavy metals and the Nemerow $P$ values, range, median values, and $C V$ in the 100 topsoil samples are shown in Table 3. On average, the $P_{i}$ indices for $\mathrm{Cu}, \mathrm{Zn}, \mathrm{Ni}, \mathrm{Pb}, \mathrm{Cr}, \mathrm{Hg}, \mathrm{As}$, and $\mathrm{Cd}$ were $0.212,0.233,0.417,0.054,0.231,0.076,0.246$, and 0.246, respectively. Different heavy metal concentrations of single pollution index are in an order of $\mathrm{Ni}>\mathrm{Cd}=\mathrm{As}>\mathrm{Zn}>$ $\mathrm{Cr}>\mathrm{Cu}>\mathrm{Hg}>\mathrm{Pb}$. The single pollution index showed that the $\mathrm{Ni}$ pollution intensity was strong. $\mathrm{Cd}, \mathrm{Cr}$, and $\mathrm{Pb}$ are considered as the most important environmental pollutants in agricultural soils because of the potential harmful effects they may have on food quality and health of soil.

The Nemerow integrated pollution index $(P)$ in this area is 0.305 , which is lower than 1 , meaning that heavy metal exposure through the food chain does not have considerable consequence and is generally safe.

3.4. Semivariogram Analysis. The semivariogram model of soil heavy metal single pollution index at both orientations is given in Figure 3. Theoretical models were then employed to interpret the experimental semivariograms and the model with the best fitting was chosen [22]. $P_{\mathrm{Ni}}$ and $P_{\mathrm{Cr}}$ were fitted with the exponential model, and the other four heavy metal single pollution indexes were all best fitted with the spherical model.

The attributes of the semivariograms for each soil heavy metal single pollution index were also summarized in Table 4 . All of the Nug/Sill ratios were less than 59.74\%, indicating random heterogeneity. The nugget effect may be caused by random factors such as data deviations, agricultural activities, or sample density. Nugget contributions highlighted the stronger spatial correlation in Table 4 . The range of semivariograms for soil heavy metal single pollution index ranged from $0.0384 \mathrm{~km}$ to $0.1192 \mathrm{~km}$. This confirmed the rational of the sampling density. 


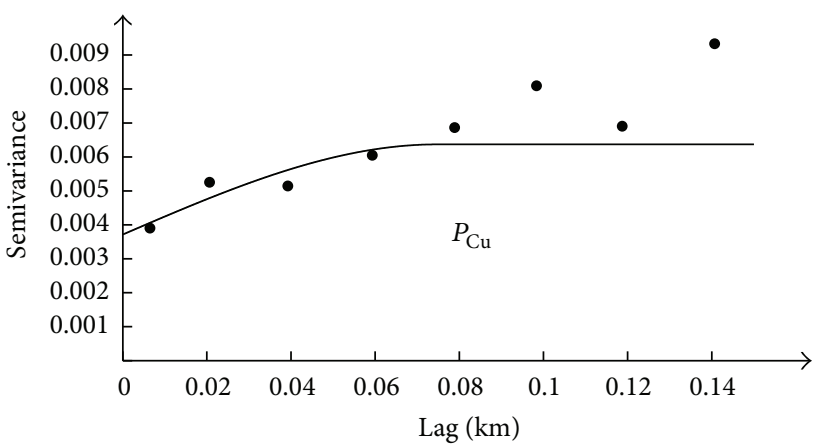

(a)

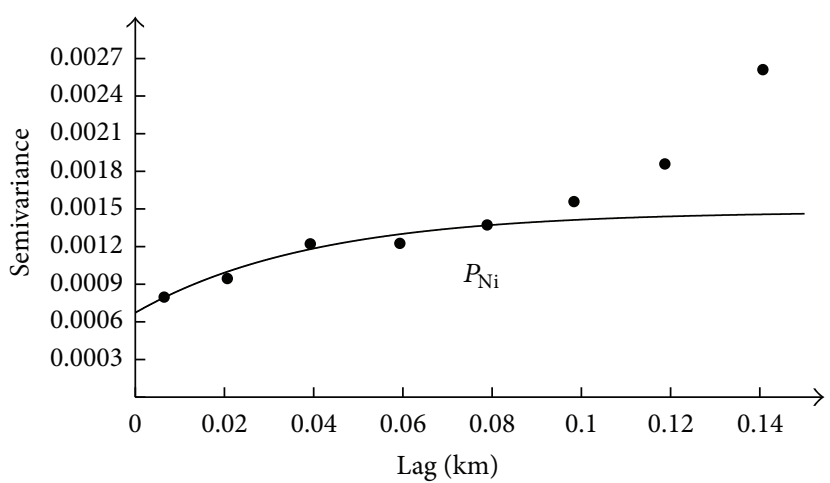

(c)

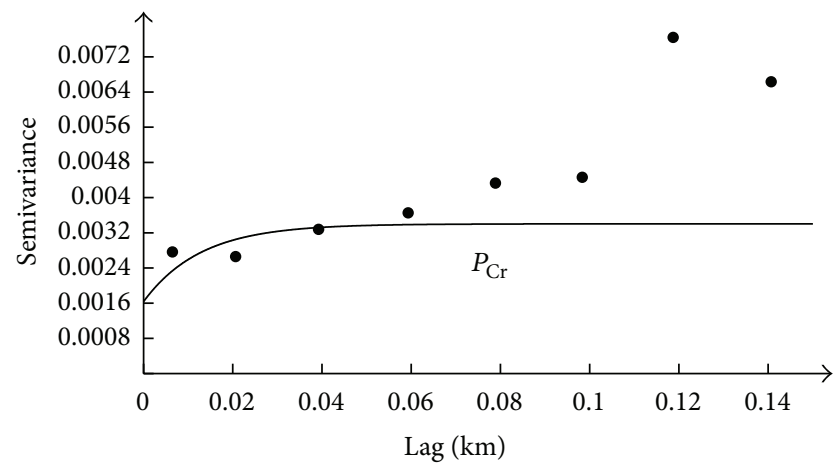

(e)

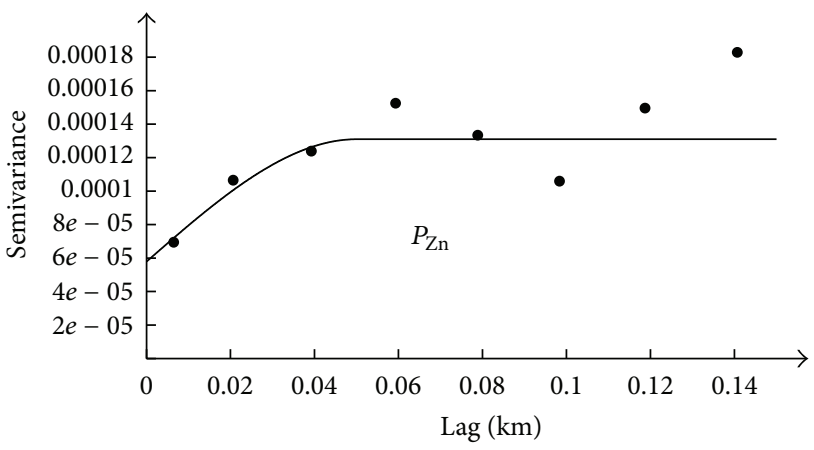

(b)

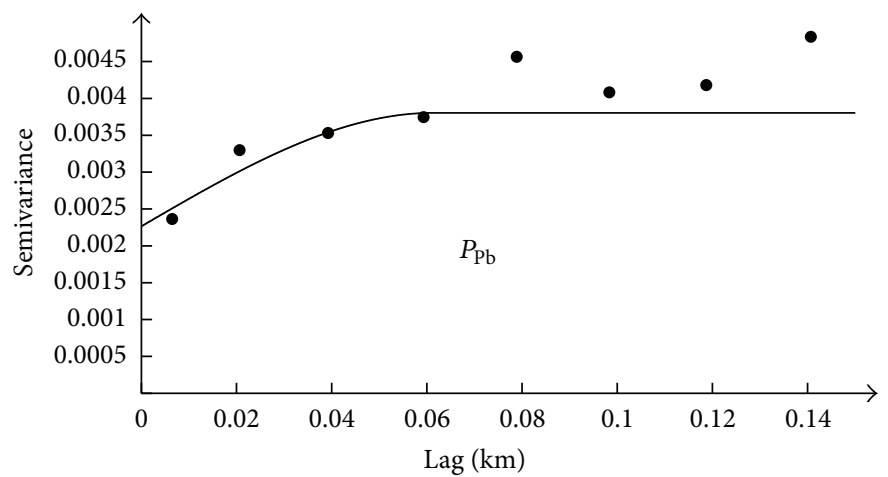

(d)

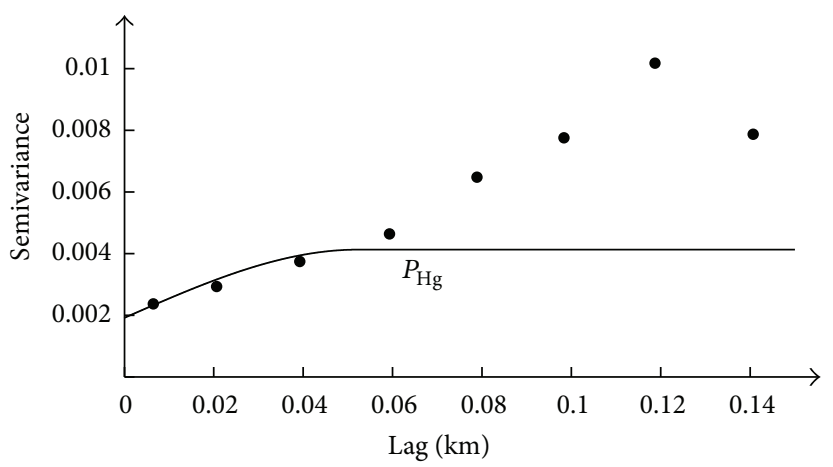

(f)

FIGURE 3: Semivariograms model of soil heavy metal single pollution index.

TABLE 2: A summary of heavy metal concentrations in agricultural soil for various areas ( $\mathrm{mg} / \mathrm{kg})$.

\begin{tabular}{lccccccccc}
\hline Area & $\mathrm{Cu}$ & $\mathrm{Zn}$ & $\mathrm{Ni}$ & $\mathrm{Pb}$ & $\mathrm{Cr}$ & $\mathrm{Hg}$ & $\mathrm{As}$ & $\mathrm{Cd}$ & References \\
\hline Zhengding & 21.22 & 69.96 & 25.04 & 18.80 & 57.77 & 0.08 & 6.16 & 0.15 & This study \\
Background value & 21.7 & 62.0 & 28.8 & 20.0 & 63.9 & 0.023 & 12.1 & 0.075 & Yang et al. (2009) [18] \\
Grade II & 100 & 300 & 60 & 350 & 250 & 1.0 & 25 & 0.6 & SEPA (1995) [24] \\
Beijing & 26.08 & 61.18 & 24.01 & 18.81 & 67.77 & 0.079 & 7.68 & 0.24 & Hu et al. (2004) \\
Beijing, Tianjin & 28.2 & 71.0 & $\mathrm{NA}$ & 18.7 & 52.3 & 0.092 & 7.9 & 0.145 & Qiao et al. (2011) [15] \\
Alicante & 22.5 & 52.8 & 20.9 & 22.8 & 26.5 & $\mathrm{NA}$ & $\mathrm{NA}$ & 0.34 & Micó et al. (2006) [6] \\
Ebro & 17.3 & 57.5 & 20.5 & 17.5 & 20.3 & 0.036 & $\mathrm{NA}$ & 0.42 & Rodriguez et al. (2006) \\
Huizhou & 21.82 & 66.15 & 20.52 & 65.38 & 43.01 & 0.24 & 12.76 & 0.12 & Cai et al. (2012) [9] \\
\hline
\end{tabular}

Grade II (the value for protection of agricultural production and human health). 
TABle 3: Descriptive statistics of soil heavy metals pollution indices.

\begin{tabular}{lccccccccc}
\hline Variable & & & \multicolumn{3}{c}{$P_{i}$} & & & \\
& $\mathrm{Cu}$ & $\mathrm{Zn}$ & $\mathrm{Ni}$ & $\mathrm{Pb}$ & $\mathrm{Cr}$ & $\mathrm{Hg}$ & $\mathrm{Cd}$ & 0.15 \\
\hline Min. & 0.111 & 0.154 & 0.215 & 0.035 & 0.131 & 0.018 & 0.087 & 0.091 \\
Max. & 0.332 & 0.293 & 0.608 & 0.117 & 0.354 & 0.374 & 0.396 & 0.483 \\
Mean & 0.212 & 0.233 & 0.417 & 0.054 & 0.231 & 0.076 & 0.246 & 0.246 & 0.521 \\
Kurt. & 1.403 & 0.430 & -0.283 & 9.317 & 1.959 & 9.669 & 0.177 & 3.142 & 1.968 \\
Skew. & 0.352 & 0.073 & -0.185 & 2.108 & 0.762 & 2.769 & -0.116 & 1.476 \\
St.d & 0.034 & 0.024 & 0.077 & 0.011 & 0.035 & 0.060 & 0.060 & 0.067 & 0.086 \\
C.V. & 16.04 & 10.30 & 18.47 & 20.37 & 15.15 & 78.95 & 24.39 & 27.24 & 39.67 \\
\hline
\end{tabular}

St.d: standard deviation, C.V.: coefficient variation.

TABLE 4: Spatial correlation for heavy metals.

\begin{tabular}{lccccc}
\hline & Model & Nugget & Sill & $C_{0} /\left(C+C_{0}\right)$ & Range \\
$(\%)$ & $C+C_{0}$ & 58.40 & 0.0746 \\
$P_{\mathrm{Cu}}$ & Spherical & 0.0037 & 0.0064 & 44.25 & 0.05 \\
$P_{\mathrm{Zn}}$ & Spherical & $5.8 e-05$ & 0.0001 & 45.58 & 0.1192 \\
$P_{\mathrm{Ni}}$ & Exponential & 0.0007 & 0.0015 & 59.74 & 0.0613 \\
$P_{\mathrm{Pb}}$ & Spherical & 0.0023 & 0.0038 & 48.24 & 0.0384 \\
$P_{\mathrm{Cr}}$ & Exponential & 0.0016 & 0.0034 & 46.49 & 0.0521 \\
$P_{\mathrm{Hg}}$ & Spherical & 0.0019 & 0.0041 & & \\
\hline
\end{tabular}

\section{Conclusions}

The single pollution index, integrated pollution index, and sources of the heavy metals $\mathrm{Cu}, \mathrm{Zn}, \mathrm{Ni}, \mathrm{Pb}, \mathrm{Cr}, \mathrm{Hg}$, As, and $\mathrm{Cd}$ in agricultural topsoil samples collected from Zhengding have been investigated in this work. The mean values of single pollution index and integrated pollution index are less than 1 in the area.

The mean values of $\mathrm{Zn}, \mathrm{Ni}, \mathrm{Pb}, \mathrm{Cr}, \mathrm{Hg}$, As, and $\mathrm{Cd}$ in the analysed soils do not exceed the limited second grade criteria environmental quality standard for soils in China (GB 156181995), which means that the soil in this area is not polluted. Only $\mathrm{Zn}, \mathrm{Hg}$, and $\mathrm{Cd}$ present higher values in some cases. The mean values of soil $\mathrm{Zn}, \mathrm{Hg}$, and $\mathrm{Cd}$ were higher than the, respectively, background values. Agrochemical inputs may play the most important role for the input of $\mathrm{Zn}$ and $\mathrm{Cd}$. The risk of $\mathrm{Hg}$ and $\mathrm{Cd}$ accumulation requires further attention and monitoring.

Multivariate statistics is found to be a powerful tool to identify the main factors determining the variability of geochemical data and interpret the measurement results. Variation of $\mathrm{Cu}, \mathrm{Zn}$, and $\mathrm{Cd}$ concentrations is controlled by anthropogenic intense agriculture activities. The concentrations of $\mathrm{Pb}$ and $\mathrm{As}$ in agricultural soil are abnormalities mainly affected by aerial deposits from gasoline exhausts, while the concentrations of $\mathrm{Ni}$ and $\mathrm{Hg}$ in agricultural soil are mainly affected by natural parent material and human activities.

\section{Conflict of Interests}

The authors declare that there is no conflict of interests regarding the publication of this paper.

\section{Acknowledgments}

The authors are grateful for the financial support of the National Natural Science Foundation of China (no. 31272258) and the Natural Science Foundation of Shanxi Province (no. 2010011044). The authors wish to thank Gao Yunfeng for assistance with soil sampling and lab analysis. They also acknowledge the valuable comments of the anonymous reviewers.

\section{References}

[1] S. S. Huang, Q. L. Liao, M. Hua et al., "Survey of heavy metal pollution and assessment of agricultural soil in Yangzhong district, Jiangsu Province, China," Chemosphere, vol. 67, no. 11, pp. 2148-2155, 2007.

[2] Y. X. Song, J. F. Ji, Z. F. Yang et al., "Geochemical behavior assessment and apportionment of heavy metal contaminants in the bottom sediments of lower reach of Changjiang River," Catena, vol. 85, no. 1, pp. 73-81, 2011.

[3] H. R. Zhao, B. C. Xia, C. Fan, P. Zhao, and S. Shen, "Human health risk from soil heavy metal contamination under different land uses near Dabaoshan Mine, Southern China," Science of the Total Environment, vol. 417-418, pp. 45-54, 2012.

[4] R. Garcia, I. Maiz, and E. Millan, "Heavy metal contamination analysis of roadsoils and grasses from Gipuzkoa (Spain)," Environmental Technology, vol. 17, no. 7, pp. 763-770, 1996.

[5] F. A. Nicholson, S. R. Smith, B. J. Alloway, C. Carlton-Smith, and B. J. Chambers, "An inventory of heavy metals inputs to agricultural soils in England and Wales," Science of the Total Environment, vol. 311, no. 1-3, pp. 205-219, 2003.

[6] C. Micó, L. Recatalá, M. Peris, and J. Sánchez, "Assessing heavy metal sources in agricultural soils of an European Mediterranean area by multivariate analysis," Chemosphere, vol. 65, no. 5, pp. 863-872, 2006. 
[7] B. J. Alloway, "The origins of heavy metals in soils," in Heavy Metals in Soils, B. J. Alloway, Ed., pp. 38-57, Blackie Academic and Professional, London, UK, 1995.

[8] A. Facchinelli, E. Sacchi, and L. Mallen, "Multivariate statistical and GIS-based approach to identify heavy metal sources in soils," Environmental Pollution, vol. 114, no. 3, pp. 313-324, 2001.

[9] L. M. Cai, Z. C. Xu, M. Ren et al., "Source identification of eight hazardous heavy metals in agricultural soils of Huizhou, Guangdong Province, China," Ecotoxicology and Environmental Safety, vol. 78, pp. 2-8, 2012.

[10] G. Wu, H. B. Kang, X. Zhang, H. B. Shao, L. Y. Chu, and C. Ruan, "A critical review on the bio-removal of hazardous heavy metals from contaminated soils: issues, progress, eco-environmental concerns and opportunities," Journal of Hazardous Materials, vol. 174, no. 1-3, pp. 1-8, 2010.

[11] P. Yang, M. Yang, and H. Shao, "Magnetic susceptibility and heavy metals distribution from risk-cultivated soil around ironsteel plant, China," Clean-Soil, Air, Water, vol. 40, no. 6, pp. 615618, 2012.

[12] A. Hani and E. Pazira, "Heavy metals assessment and identification of their sources in agricultural soils of Southern Tehran, Iran," Environmental Monitoring and Assessment, vol. 176, no. 14, pp. 677-691, 2011.

[13] W. Huang, R. Campredon, J. J. Abrao, M. Bernat, and C. Latouche, "Variation of heavy metals in recent sediments from Piratininga Lagoon (Brazil): interpretation of geochemical data with the aid of multivariate analysis," Environmental Geology, vol. 23, no. 4, pp. 241-247, 1994.

[14] S. Dragović and N. Mihailović, "Analysis of mosses and topsoils for detecting sources of heavy metal pollution: multivariate and enrichment factor analysis," Environmental Monitoring and Assessment, vol. 157, no. 1-4, pp. 383-390, 2009.

[15] M. Qiao, C. Cai, Y. Huang, Y. Liu, A. Lin, and Y. Zheng, "Characterization of soil heavy metal contamination and potential health risk in metropolitan region of northern China," Environmental Monitoring and Assessment, vol. 172, no. 1-4, pp. 353-365, 2011.

[16] K. L. Hu, F. R. Zhang, Y. Z. Lu, R. Wang, and Y. Xu, "Spatial distribution of concentrations of soil heavy metals in Daxing county, Beijing," Acta Scientiate Circumstantiae, vol. 24, no. 3, pp. 463-469, 2011.

[17] F. Ruiz, M. L. González-Regalado, J. Borrego, J. A. Morales, J. G. Pendón, and J. M. Muñoz, "Stratigraphic sequence, elemental concentrations and heavy metal pollution in Holocene sediments from the Tinto-Odiel Estuary, southwestern Spain," Environmental Geology, vol. 34, no. 4, pp. 270-278, 1998.

[18] P. Yang, R. Mao, H. Shao, and Y. Gao, "The spatial variability of heavy metal distribution in the suburban farmland of Taihang Piedmont Plain, China," Comptes Rendus-Biologies, vol. 332, no. 6, pp. 558-566, 2009.

[19] A. Franco-Uría, C. López-Mateo, E. Roca, and M. L. FernándezMarcos, "Source identification of heavy metals in pastureland by multivariate analysis in NW Spain," Journal of Hazardous Materials, vol. 165, no. 1-3, pp. 1008-1015, 2009.

[20] R. J. Yao, J. S. Yang, P. Gao, H. B. Shao, X. B. Chen, and S. P. Yu, "Multivariate simulation and assessment of three dimensional spatial patterns of coastal soil salinity using ancillary variables," Fresenius Environmental Bulletin, vol. 22, no. 1, pp. 39-52, 2013.

[21] E. H. Isaaks and R. M. Srivastava, An Introduction to Applied Geostatistics, Oxford University Press, New York, NY, USA, 1989.
[22] R. J. Yao, J. S. Yang, and H. B. Shao, "Accuracy and uncertainty assessment on geostatistical simulation of soil salinity in a coastal farmland using auxiliary variable," Environmental Monitoring and Assessment, vol. 185, no. 6, pp. 5151-5164, 2013.

[23] P. Goovaerts, "A coherent geostatistical approach for combining choropleth map and field data in the spatial interpolation of soil properties," European Journal of Soil Science, vol. 62, no. 3, pp. 371-380, 2011.

[24] SEPA, "State environmental protection administration of China," Environmental Quality Standard for Soils GB156181995, SEPA, Beijing, China, 1995.

[25] Z. P. Yang, W. X. Lu, Y. Q. Long, X. H. Bao, and Q. C. Yang, "Assessment of heavy metals contamination in urban topsoil from Changchun City, China," Journal of Geochemical Exploration, vol. 108, no. 1, pp. 27-38, 2011.

[26] Y. B. Huang, Y. B. Lan, S. J. Thomson, A. Fang, W. C. Hoffmann, and R. E. Lacey, "Development of soft computing and applications in agricultural and biological engineering," Computers and Electronics in Agriculture, vol. 71, no. 2, pp. 107127, 2010.

[27] H. B. Shao, Ed., Metal Contamination: Sources, Detection and Environmental Impact, Nova Science, New York, NY, USA, 2012. 

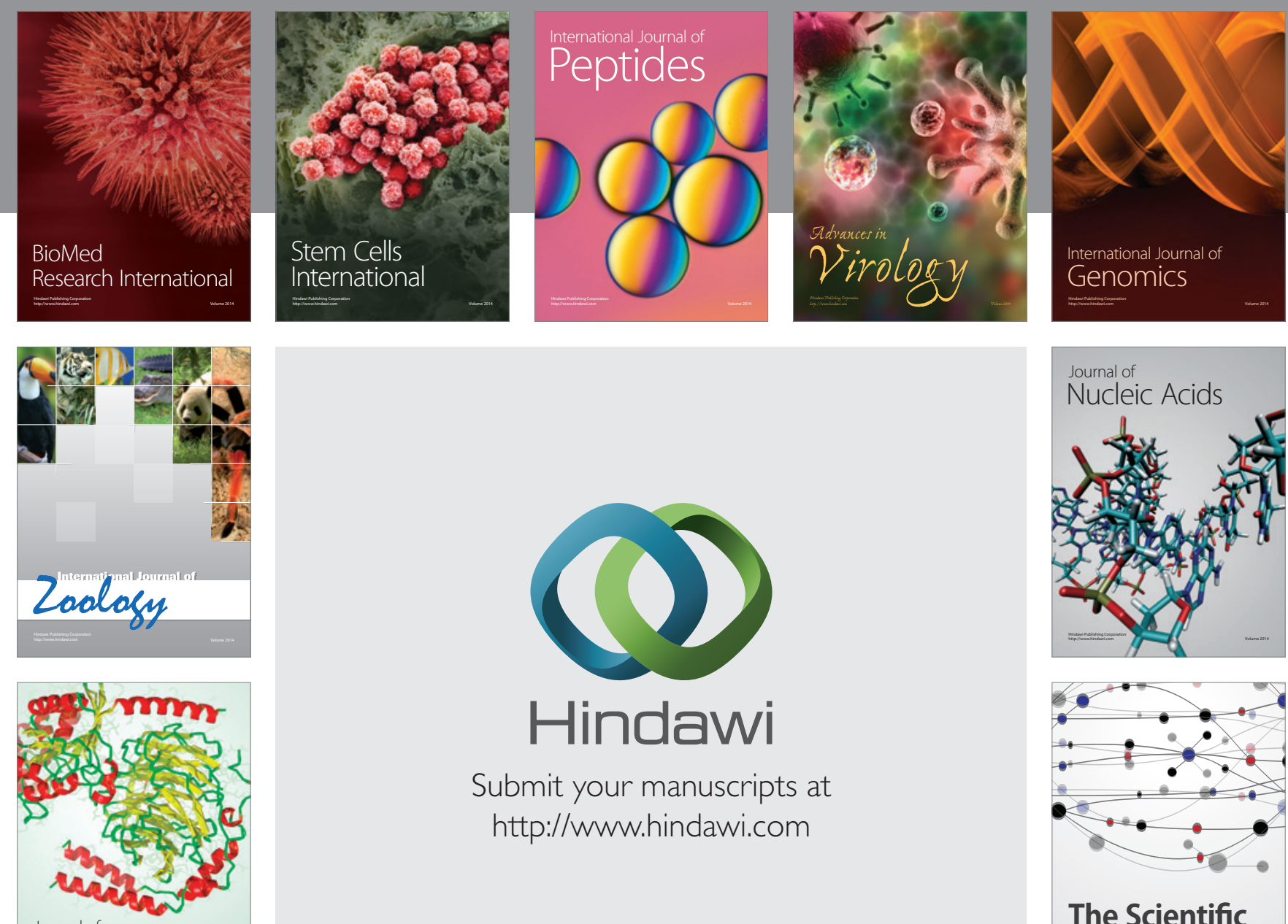

Submit your manuscripts at

http://www.hindawi.com

Journal of
Signal Transduction
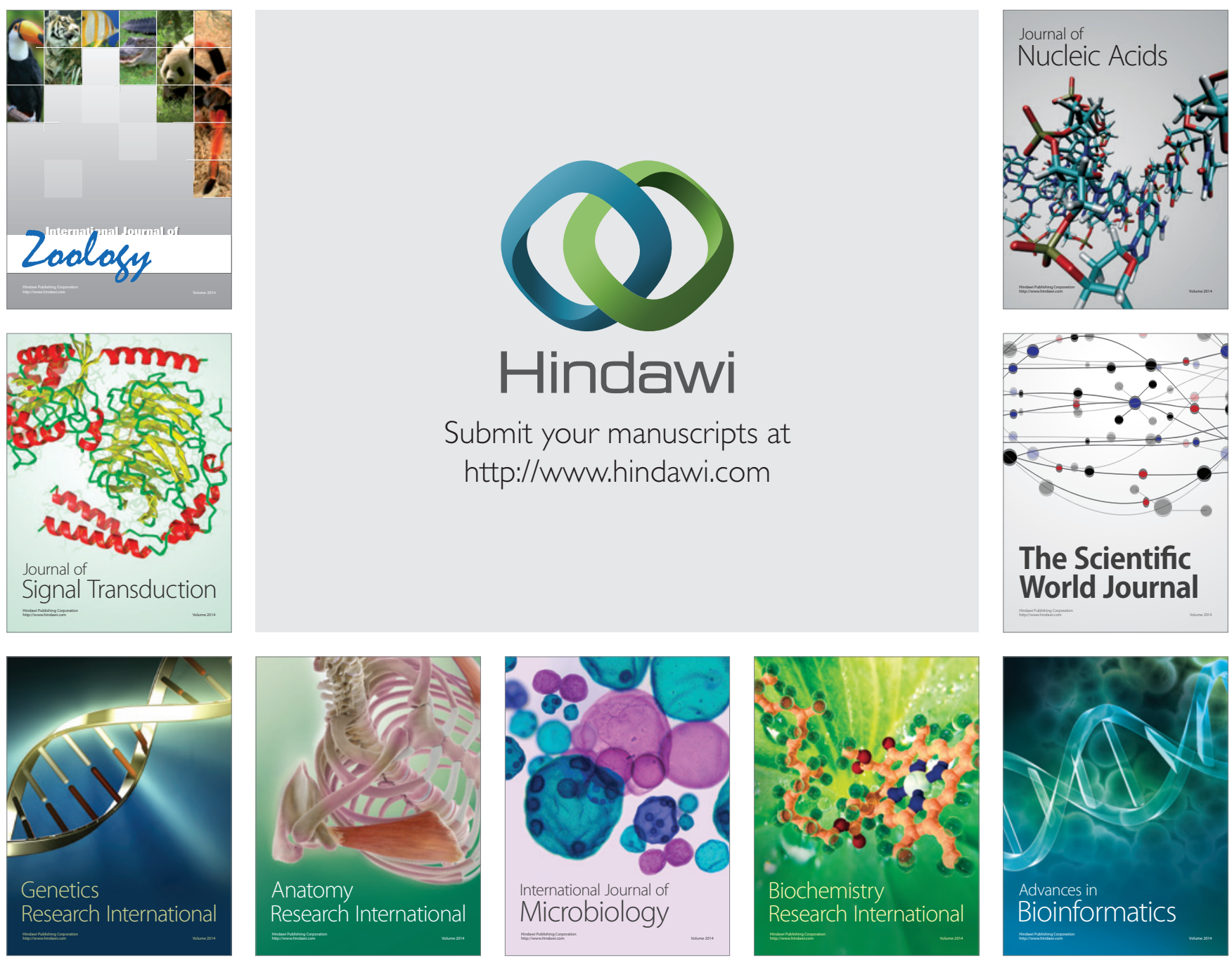

The Scientific World Journal
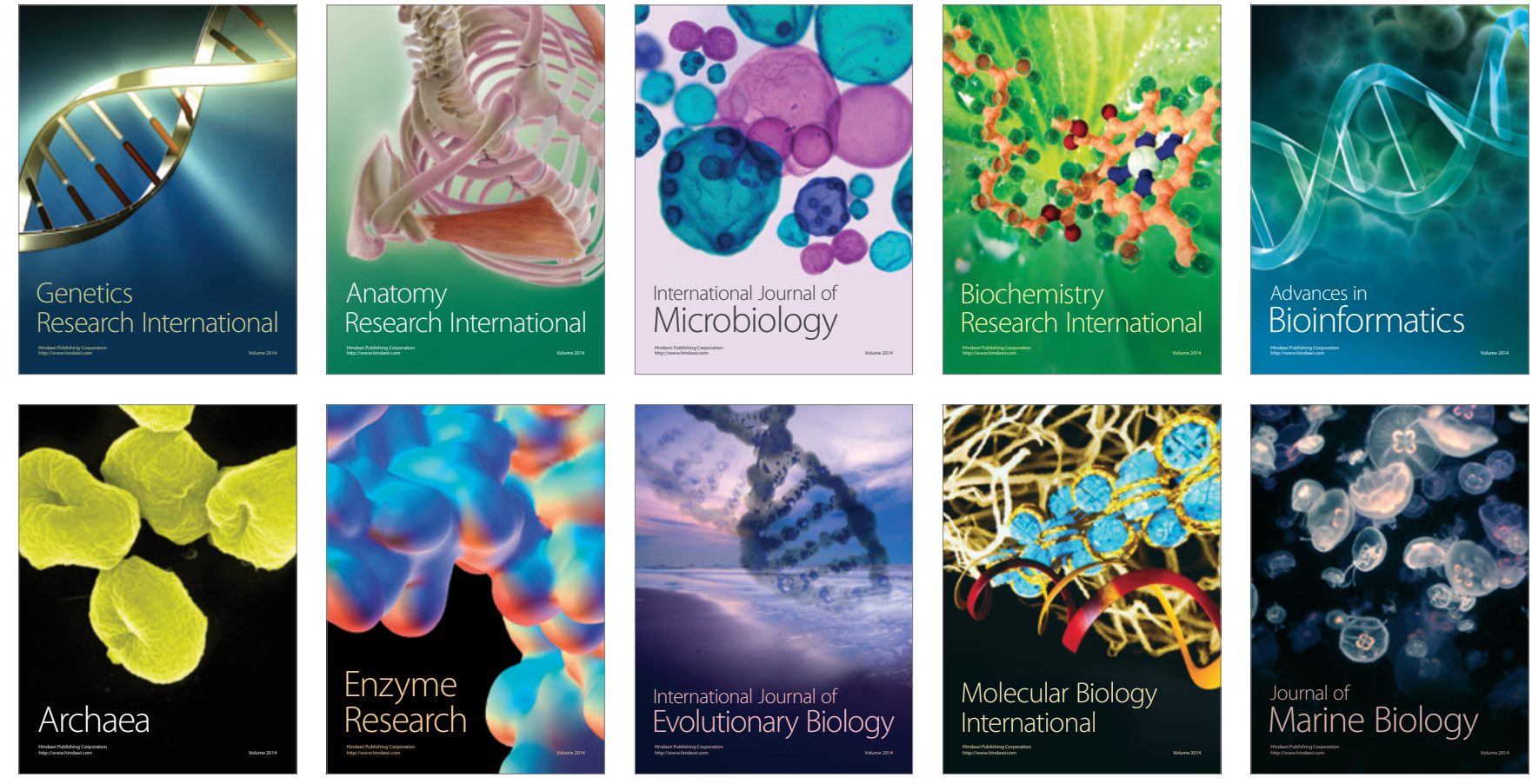